\title{
Kinetic Studies of the Solvolyses of Isopropenyl Chloroformate
}

\author{
Han Joong Koh* and Suk Jin Kang
Department of Science Education, Jeonju National University of Education, Jeonju 560-757, Korea
${ }^{*}$ E-mail: hankoh@jnue.kr
Received March 30, 2010, Accepted April 8, 2010

Key Words: Isopropenyl chloroformate, Extended Grunwald-Winstein equation, Addition-Elimination mechanism

The mechanism of acyl-transfer reactions have been investigated intensively for many years both experimentally ${ }^{1}$ and theoretically. ${ }^{2}$ The mechanisms of most of these reactions are, however, still not well established. The bimolecular solvolysis of acyl halides (RCOX) is believed to proceed either through a direct displacement mechanism $\left(\mathrm{S}_{\mathrm{N}} 2\right)$ or through an associative addition-elimination mechanism involving a tetrahedral intermediate. ${ }^{3}$ For acyl halides with a strong electron donating group, a dissociative mechanism involving an acylium ion intermediate has also been invoked. ${ }^{4}$ The two types of mechanism, $\mathrm{S}_{\mathrm{N}} 2$ and stepwise addition-elimination, are also common for the bimolecular aminolysis of acyl halides. The aminolyses of acetyl chloride, $\mathrm{MeCOCl}$, and methyl chloroformate, $\mathrm{MeOC}$ $\mathrm{OCl}$, have been proposed to proceed by rate-limiting breakdown of a zwitterionic tetrahedral intermediate, $\mathrm{T}^{ \pm}$, for weakly basic amines with a change to rate-limiting attack for more basic amines. $^{5}$

The equation (1) represents the most general form of the solvolyses of several chloroformate esters. The dialkyl or alkyl aryl carbonate is formed by

$$
\begin{aligned}
& \mathrm{ROCOCl}+\mathrm{SOH} / \mathrm{H}_{2} \mathrm{O} \rightarrow \\
& \mathrm{ROCOOS}+\mathrm{ROS}+\mathrm{ROH}+\mathrm{CO}_{2}+\mathrm{HCl}
\end{aligned}
$$

nucleophilic attack of alcohol (SOH) at the acyl carbon. The alcohol or phenol product is formed either by a parallel attack by water to give the hydrogen carbonate ester, followed by the loss of $\mathrm{CO}_{2}$, ${ }^{6}$ or by the attack of water on $\mathrm{R}^{+}$, formed by the loss of $\mathrm{CO}_{2}$ from an intermediate carboxylium ion (ROCO $)^{+}$. Capture of the $\mathrm{R}^{+}$by $\mathrm{SOH}$ leads to the ester (ROS) and capture by the chloride ion formed in the ionization will lead to a decom-

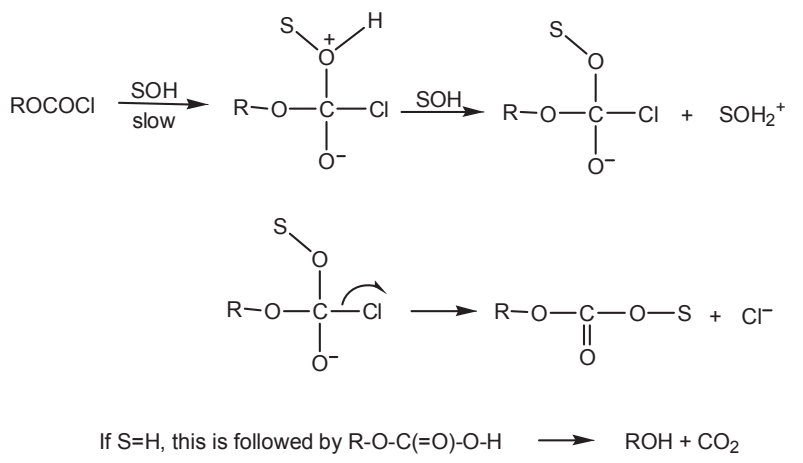

position pathway (for the chloroformate ester reactant) to give $\mathrm{RCl}$. When feasible, an alternative decomposition pathway, involving the extraction of a $\beta$-proton from the $\mathrm{R}$ group and alkene formation, can also occur.

Two types of mechanism have been found to operate, postulated as an addition-elimination mechanism (Scheme 1), with the addition being rate limiting, and an ionization mechanism ${ }^{7 \mathrm{a}}$ (Scheme 2).

The extended Grunwald-Winstein equation ${ }^{8}$ is used to correlate the rate constants of solvolysis reactions in terms of solvent ionizing power ${ }^{8 \mathrm{a}-\mathrm{e}}$ and solvent nucleophilicity. ${ }^{8 \mathrm{f}-\mathrm{h}}$ In equation (2), $k$ and $k_{o}$ represent the rate constants of solvolysis in a given solvent and in a standard solvent ( $80 \%$ ethanol), respectively; $l$ represents the sensitivity to changes in solvent nucleophilicity $\left(\mathrm{N}_{\mathrm{T}}\right) ; m$ represents the sensitivity to changes in the solvent ionizing power $\left(\mathrm{Y}_{\mathrm{X}}\right.$, for a leaving group $\left.\mathrm{X}\right)$; and c represents a constant (residual) term.

$$
\log \left(k / k_{o}\right)=l \mathrm{~N}_{\mathrm{T}}+m \mathrm{Y}_{\mathrm{X}}+\mathrm{c}
$$

In view of the often suggested mechanistic change for solvolysis of chloroformate esters from rate-limiting ionization (for alkyl groups R in ROCOCl with concurrent or subsequent fragmentation) to addition-elimination with the addition step rate-limiting, we conducted kinetic studies on the solvolysis reactions of isopropenyl chloroformate (I) in pure and binary solvents, as shown (for an aqueous alcohol solvents) in equation (3). For non-solvolytic substitutions, it has been proposed that variation in the $\mathrm{R}$ group of ROCOX can lead to a change in the rate-limiting step $(r l s)$ from addition to elimination within the addition-elimination mechanism. ${ }^{9}$
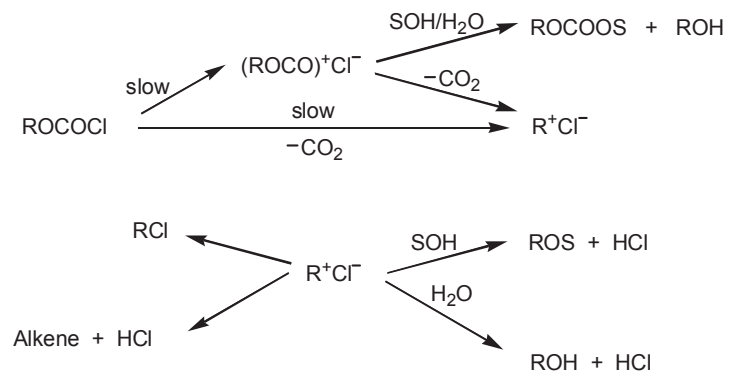
Table 1. Rate constants of solvolysis of isopropenyl chloroformate ${ }^{a}$ in various pure and mixed solvents at $35.0^{\circ} \mathrm{C}$, as well as the $\mathrm{N}_{\mathrm{T}}$ and $\mathrm{Y}_{\mathrm{Cl}}$ values for the solvents

\begin{tabular}{ccrr}
\hline Solvent $^{b}$ & $10^{3} k^{c}\left(\mathrm{~s}^{-1}\right)$ & $\mathrm{N}_{\mathrm{T}}{ }^{d}$ & $\mathrm{Y}_{\mathrm{Cl}}{ }^{e}$ \\
\hline $100 \%$ EtOH & $1.58 \pm 0.02$ & 0.37 & -2.52 \\
$90 \% \mathrm{EtOH}$ & $2.45 \pm 0.02$ & 0.16 & -0.94 \\
$80 \%$ EtOH & $3.47 \pm 0.04$ & 0.0 & 0.0 \\
$70 \%$ EtOH & $4.37 \pm 0.03$ & -0.20 & 0.78 \\
$60 \% \mathrm{EtOH}$ & $4.79 \pm 0.03$ & -0.38 & 1.38 \\
$50 \%$ EtOH & $7.24 \pm 0.04$ & -0.58 & 2.02 \\
$40 \%$ EtOH & $11.2 \pm 0.3$ & -0.74 & 2.75 \\
$20 \%$ EtOH & $28.2 \pm 0.5$ & -1.16 & 4.09 \\
$100 \% \mathrm{MeOH}$ & $4.79 \pm 0.03$ & 0.17 & -1.20 \\
$90 \% \mathrm{MeOH}$ & $9.55 \pm 0.04$ & -0.01 & -0.20 \\
$80 \% \mathrm{MeOH}$ & $14.1 \pm 0.5$ & -0.06 & 0.67 \\
$70 \% \mathrm{MeOH}$ & $22.9 \pm 0.4$ & -0.40 & 1.46 \\
$60 \% \mathrm{MeOH}$ & $33.1 \pm 0.4$ & -0.54 & 2.07 \\
$50 \% \mathrm{MeOH}$ & $49.0 \pm 0.6$ & -0.75 & 2.70 \\
$40 \% \mathrm{MeOH}$ & $66.1 \pm 0.5$ & -0.87 & 3.25 \\
$90 \%$ Acetone & $0.282 \pm 0.002$ & -0.35 & -2.39 \\
$80 \%$ Acetone & $0.525 \pm 0.004$ & -0.37 & -0.83 \\
$70 \%$ Acetone & $1.12 \pm 0.03$ & -0.42 & 0.17 \\
$60 \%$ Acetone & $2.82 \pm 0.03$ & -0.52 & 1.00 \\
$50 \%$ Acetone & $3.80 \pm 0.04$ & -0.70 & 1.73 \\
$40 \%$ Acetone & $8.91 \pm 0.05$ & -0.83 & 2.46 \\
$20 \%$ Acetone & $28.2 \pm 0.3$ & -1.11 & 3.77 \\
$90 \% \mathrm{TFE}{ }^{g}$ & $0.0525 \pm 0.0003$ & -2.55 & 2.85 \\
$80 \% \mathrm{TFE}$ & $0.0776 \pm 0.0004$ & -2.19 & 2.90 \\
$70 \% \mathrm{TFE}$ & $0.123 \pm 0.002$ & -1.98 & 2.96 \\
$50 \% \mathrm{TFE}$ & $0.575 \pm 0.005$ & -1.73 & 3.16 \\
$90 \% \mathrm{HFIP}$ & $0.00219 \pm 0.00003$ & -3.84 & 4.31 \\
$70 \% \mathrm{HFIP}$ & $0.0141 \pm 0.0003$ & -2.94 & 3.83 \\
$50 \% \mathrm{HFIP}$ & $0.0891 \pm 0.0006$ & -2.49 & 3.80 \\
$80 \mathrm{~T}-20 \mathrm{E}^{h}$ & $0.0282 \pm 0.0003$ & -1.76 & 1.89 \\
$60 \mathrm{~T}-40 \mathrm{E}$ & $0.0776 \pm 0.0004$ & -0.94 & 0.63 \\
$40 \mathrm{~T}-60 \mathrm{E}$ & $0.174 \pm 0.002$ & -0.34 & -0.48 \\
$20 \mathrm{~T}-80 \mathrm{E}$ & $0.363 \pm 0.003$ & 0.08 & -1.42 \\
\hline
\end{tabular}

${ }^{a}$ Unless otherwise indicated, a $10^{-3} \mathrm{M}$ solution of the substrate in the indicated solvent, containing $0.1 \% \mathrm{CH}_{3} \mathrm{CN}$. ${ }^{b} \mathrm{On}$ a volume-volume content at $25.0^{\circ} \mathrm{C}$, other component is water. ${ }^{c}$ With associated standard deviations. ${ }^{d}$ Values from ref. 8f. ${ }^{e}$ Values from ref. 8. ${ }^{f}$ Values of $k(=2.19( \pm 0.04) \times$ $\left.10^{-3} \mathrm{~s}^{-1}\right)$ in methanol- $d$ (MeOD), corresponding to a $k_{\mathrm{MeOH}} / k_{\mathrm{MeOD}}$ value of $2.19 \pm 0.04$ [with associated standard error (Crumpler, T. B.; Yoh, J. H. Chemical Computations and Error; Wiley: New York, 1940; p 178)]. ${ }^{g}$ Solvent prepared on a weight-weight basis at $25.0^{\circ} \mathrm{C}$. The other component is water. ${ }^{h} \mathrm{~T}-\mathrm{E}$ indicates TFE-EtOH mixtures.

In addition to the application of the extended Grunwald-Winstein equation to the rate constants, the influence of temperature on the rate constants in the five solvents has been discussed by calculating activation enthalpies and entropies. To get further mechanistic information from the kinetic solvent isotope effect, the kinetic runs were performed in both deuterated methanol (MeOD) and normal methanol $(\mathrm{MeOH})$.

\section{Results and Discussion}

The solvolysis rate constants $(k)$ of isopropenyl chloroformate (I) in 33 pure and binary solvents at $35.0{ }^{\circ} \mathrm{C}$ are summarized
Table 2. Rate constants and activation parameters for the solvolyses of isopropenyl chloroformate ${ }^{a}$ in pure and aqueous solvents at various temperatures

\begin{tabular}{|c|c|c|c|c|}
\hline Solvent & $\begin{array}{l}\text { Temp. } \\
\left({ }^{\circ} \mathrm{C}\right)\end{array}$ & $10^{3} k^{b}\left(\mathrm{~s}^{-1}\right)$ & $\begin{array}{c}\Delta \mathrm{H}^{\ddagger} \\
\left(\mathrm{kcal} \cdot \mathrm{mol}^{-1}\right)^{c}\end{array}$ & $\begin{array}{c}-\Delta \mathrm{S}^{\neq} \\
\left(\mathrm{cal} \cdot \mathrm{mol}^{-1} \cdot \mathrm{K}^{-1}\right)\end{array}$ \\
\hline \multirow{4}{*}{$100 \% \mathrm{EtOH}$} & 25 & $0.814 \pm 0.003$ & \multirow{4}{*}{$11.9 \pm 0.1$} & \multirow{4}{*}{$33.9 \pm 1.3$} \\
\hline & 35 & $1.58 \pm 0.02$ & & \\
\hline & 45 & $3.05 \pm 0.03$ & & \\
\hline & 55 & $5.86 \pm 0.03$ & & \\
\hline \multirow{4}{*}{$80 \% \mathrm{EtOH}^{d}$} & 25 & $1.92 \pm 0.02$ & \multirow{4}{*}{$10.9 \pm 0.1$} & \multirow{4}{*}{$34.2 \pm 0.3$} \\
\hline & 35 & $3.47 \pm 0.04$ & & \\
\hline & 45 & $6.42 \pm 0.05$ & & \\
\hline & 55 & $11.8 \pm 0.3$ & & \\
\hline \multirow{4}{*}{$100 \% \mathrm{MeOH}$} & 25 & $2.48 \pm 0.02$ & \multirow{4}{*}{$11.8 \pm 0.1$} & \multirow{4}{*}{$30.9 \pm 0.4$} \\
\hline & 35 & $4.79 \pm 0.03$ & & \\
\hline & 45 & $9.10 \pm 0.05$ & & \\
\hline & 55 & $17.5 \pm 0.6$ & & \\
\hline \multirow{4}{*}{$80 \%$ Acetone $^{d}$} & 25 & $0.287 \pm 0.002$ & \multirow{4}{*}{$11.1 \pm 0.1$} & \multirow{4}{*}{$37.3 \pm 0.3$} \\
\hline & 35 & $0.525 \pm 0.004$ & & \\
\hline & 45 & $0.971 \pm 0.005$ & & \\
\hline & 55 & $1.83 \pm 0.02$ & & \\
\hline \multirow{4}{*}{$70 \% \mathrm{TFE}^{e}$} & 25 & $0.064 \pm 0.004$ & \multirow{4}{*}{$11.8 \pm 0.2$} & \multirow{4}{*}{$38.2 \pm 0.5$} \\
\hline & 35 & $0.123 \pm 0.002$ & & \\
\hline & 45 & $0.234 \pm 0.003$ & & \\
\hline & 55 & $0.451 \pm 0.003$ & & \\
\hline
\end{tabular}

${ }^{a} \mathrm{~A} 10^{-3} \mathrm{M}$ solution of the substrate in the indicated solvent, also containing $0.1 \% \mathrm{CH}_{3} \mathrm{CN}$. ${ }^{b}$ Averages of three or more runs, with standard deviation. ${ }^{c}$ The activation parameters are accompanied by the standard error. ${ }^{d} \mathrm{On}$ a volume-volume content at $25.0^{\circ} \mathrm{C}$. The other component is water. ${ }^{e}$ Solvent prepared on a weight-weight basis at $25.0^{\circ} \mathrm{C}$. The other component is water.

in Table 1.

The rate constants were observed to increase with increasing water content for binary aqueous mixtures. The activation parameters, $\Delta \mathrm{H}^{\neq}$and $\Delta \mathrm{S}^{\neq}$, for solvolysis of $I$ in Table 2 are consistent with the proposed addition-elimination mechanism, with the addition step rate-limiting. The small positive $\Delta \mathrm{H}^{\neq}$values $\left(10.9 \sim 11.9 \mathrm{k} \cdot \mathrm{cal}^{\prime} \cdot \mathrm{mol}^{-1}\right)$ and large negative $\Delta \mathrm{S}^{\neq}$values $(-30.9 \sim$ $-38.2 \mathrm{cal} \cdot \mathrm{mol}^{-1} \cdot \mathrm{K}^{-1}$ ) are the expected characteristics for a relatively late transition state (TS) with a large degree of bond making. ${ }^{10}$ The $\Delta \mathrm{S}^{\neq}$values are in the range normally observed for associative $S_{N} 2$ reactions or for addition-elimination reactions with the addition step rate-limiting.

Application of equation (2) to the solvolyses of I led to only moderately good correlations, with dispersal for different binary mixtures. For 33 solvents, values were obtained $1.49 \pm 0.11$ for $l, 0.52 \pm 0.06$ for $m$, and 0.18 for $\mathrm{c}$; the standard error of the estimate was 0.16 , and the correlation coefficient(r) was 0.928 . Inspection of the plot corresponding to this correlation indicated that the four data points for solvolysis in TFE-ethanol mixtures lay below the plot. Recalculation with omission of these points led to values for $l$ of $1.42 \pm 0.09$, for $m$ of $0.46 \pm 0.05$, and for $\mathrm{c}$ of 0.30 (Figure 1); the standard error of the estimate was 0.09 , and the $\mathrm{R}$ value was 0.949 . In addition, in earlier correlations of other solvolyses, data points for these TFE-ethanol solvent systems usually lay below the correlation line. ${ }^{7,11,12}$

The $l$ and $m$ values for the solvolysis of I are also compared with recently reported results involving analysis in terms of 


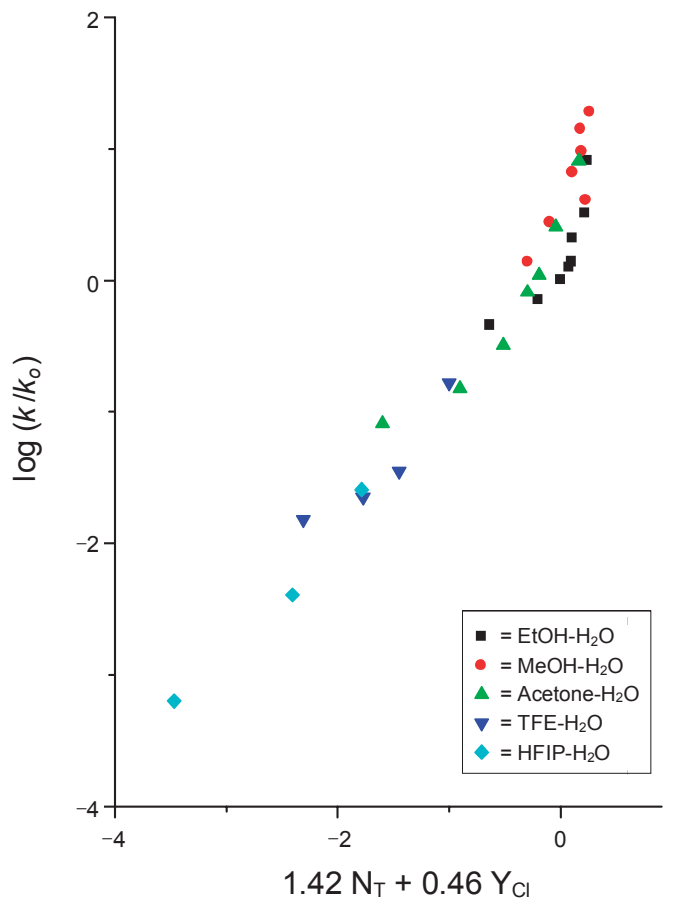

Figure 1. Plot of $\log \left(k / k_{o}\right)$ for solvolyses of isopropenyl chloroformate at $35.0{ }^{\circ} \mathrm{C}$ against $\left(1.42 \mathrm{~N}_{\mathrm{T}}+0.46 \mathrm{Y}_{\mathrm{Cl}}\right)$.

equation (2) for the rate constants of solvolyses of $n$-octyl fluoroformate $(l=1.89, m=0.79){ }^{7 \mathrm{a}}$ phenyl chloroformate $(l=1.18$, $m=0.57),{ }^{11}$ methyl chloroformate $(l=1.59, m=0.58),{ }^{12}$ and ethyl chloroformate $(l=1.56, m=0.55) .^{7 \mathrm{~b}}$ The $l$ value of 1.42 and the $m$ value of 0.46 for the solvolysis of I were similar to the previously reported values for the bimolecular solvolyses of the other substrates, which suggests a similar addition-elimination mechanism involving rate-limiting attack by the solvent at the carbonyl carbon atom of $\mathbf{I}^{13}$

For isopropenyl chloroformate, the values for the ratio $\mathrm{l} / \mathrm{m}$ of 3.09 is similar to those previously observed for the solvolyses of n-octyl fluoroformate $(\mathrm{l} / \mathrm{m}=2.28){ }^{7 \mathrm{a}}$ phenyl chloroformate $(\mathrm{l} / \mathrm{m}=2.98),{ }^{11}$ methyl chloroformate $(\mathrm{l} / \mathrm{m}=2.74),{ }^{12}$ and ethyl chloroformate $(\mathrm{l} / \mathrm{m}=2.84)^{7 \mathrm{~b}}$, which have been shown to solvolyze over a wide range of solvent type with the addition step of an addition-elimination pathway being rate limiting.

This mechanism is also consistent with general base catalysis by a second $\mathrm{MeOH}$ molecule to an attack of $\mathrm{MeOH}$ on the carbonyl carbon as evidenced by the relatively large kinetic solvent isotope effect observed, $k_{\mathrm{MeOH}} / k_{\mathrm{MeOD}}=2.19$. The kinetic solvent isotope effects for the methanolysis of benzoyl chlorides are slightly smaller $\left(k_{\mathrm{MeOH}} / k_{\mathrm{MeOD}}=1.2-1.6\right)$ for the electrondonating substituents but are similar for the electron-withdrawing substituents $\left(k_{\mathrm{MeOH}} / k_{\mathrm{MeOD}}=1.7-2.3\right) .{ }^{14}$ Reported values have indicated that values in these ranges can be considered as good supporting evidence for the postulation of a bimolecular mechanism for the methanolysis.

\section{Conclusions}

The solvolyses of the isopropenyl chloroformate proceeded rather rapidly at $35.0{ }^{\circ} \mathrm{C}$ and the progress of the reaction as a function of time can be conveniently monitored using a rapidresponse conductivity technique. For five typical solvents, the activation parameters were determined and the large negative entropies of activation were consistent with a bimolecular process.

Application of the extended Grunwald-Winstein equation (equation 2) in 33 solvents led to an $l$ value of 1.42 and an $m$ value of 0.46 (correlation coefficient of 0.949 ). These values are shown to be similar to the previously determined values for a mechanism involving rate-limiting addition in an addition-elimination pathway. The kinetic solvent isotope effect is also very close to the literature values for the solvolyses of other chloroformate esters and it is consistent with general-base catalysis being super imposed upon a bimolecular process.

\section{Experimental}

Solvents were purified as previously described. ${ }^{13}$ The substrate did not react with the pure acetonitrile within the stock solution. The isopropenyl chloroformate (Aldrich 97\%) was used as received.

The kinetic experiments were carried out by allowing a conductivity cell containing $12.5 \mathrm{~mL}$ of solvent to equilibrate, with stirring, in a constant-temperature water bath. A $12 \mu \mathrm{L}$ portion of a $1.0 \mathrm{~mol} \mathrm{dm}^{-3}$ stock solution of $\mathbf{I}$ in acetonitrile was then added. The monitoring of increases in conductivity with time and the calculation of the rate constants were conducted as previously reported. ${ }^{13}$ The multiple regression analyses were performed using commercially available packages.

\section{References}

1. (a) Bender, M. L. Chem. Rev. 1960, 60, 53. (b) The Chemistry of the Carbonyl Group; Patai, S., Ed.; Interscience: New York, 1966, 1970, Vols. 1 and 2. (c) Jencks, W. P. Catalysis in Chemistry and Enzymology; McGraw-Hill: New York, 1968. (d) Jencks, W. P. Acc. Chem. Res. 1980, 13, 161. (e) Guthrie, J. P. Acc. Chem. Res. 1983, 16, 22. (f) Baer, S.; Brinkman, E. A.; Brauman, J. I. J. Am. Chem. Soc. 1991, 113, 805. (g) Williams, A. Chem. Soc. Rev. 1994, 23, 93 .

2. (a) Yamabe, S.; Minato, T. J. Org. Chem. 1983, 48, 2972. (b) Blake, J. F.; Jorgensen, W. L. J. Am. Chem. Soc. 1987, 109, 3856. (c) Madura, J. D.; Jorgensen, W. L. J. Am. Chem. Soc. 1986, 108, 2517. (d) Park, Y. S.; Kim, C. K.; Lee, B. S.; Lee, I.; Lim, W. M.; Kim, W. K. J. Phys. Org. Chem. 1995, 8, 325.

3. (a) Bentley, T. W.; Jones, R. O. J. Chem. Soc., Perkin Trans. 2 1993, 2351. (b) Bentley, T. W.; Shim, C. S. J. Chem. Soc., Perkin Trans 2 1993, 1659. (c) Song, B. D.; Jencks, W. P. J. Am. Chem. Soc. 1989, 111, 8470. (d) Kivinen, A. The Chemistry of Acyl Halides; Patai, S., Ed.; Interscience: New York, 1972. (e) Queen, A. Can. J. Chem. 1967, 45, 1619.

4. (a) Kim, S. C.; Song, H. S.; Lee, I. J. Korean Chem. Soc. 1979, 23, 368. (b) Johnson, S. L. Adv. Phys. Org. Chem. 1967, 5, 237. (c) D'Souza, M. J.; Kevill, D. N.; Bentley, T. W.; Devaney, A. C. J. Org. Chem. 1995, 60, 1632.

5. (a) Bond, P. M.; Castro, E. A.; Moodie, R. B. J. Chem. Soc., Perkin Trans. 2 1976, 68. (b) Palling, D. J.; Jencks, W. P. J. Am. Chem. Soc. 1984, 106, 4869.

6. (a) Faurholt, C.; Gjaldbaek, J. C. Dansk. Tids. Farm. 1945, 19, 255. (b) Faurholt, C.; Gjaldbaek, J. C. Chem. Abstr. 1946, 40, 513.

7. (a) Kevill, D. N.; D’Souza, M. J. J. Chem. Soc., Perkin Trans. 2 
2002, 240. (b) Kevill, D. N.; D’Souza, M. J. J. Org. Chem. 1998, 63,2120 .

8. (a) Grunwald, E.; Winstein, S. J. Am. Chem. Soc. 1948, 70, 846. (b) Bentley, T. W.; Llewellyn, G. Prog. Phys. Org. Chem. 1990, 17, 121. (c) Kevill, D. N.; D'Souza, M. J. J. Chem. Res. Synop. 1993, 174. (d) Bentley, T. W.; Carter, G. E. J. Am. Chem. Soc. 1982, 104, 5741. (e) Koo, I. S.; Bentley, T. W.; Kang, D. H.; Lee, I. J. Chem. Soc., Perkin Trans. 2 1991, 296. (f) Winstein, S.; Grunwald, E.; Jones, H. W. J. Am. Chem. Soc. 1951, 73, 2700. (g) Kevill, D. N.; Anderson, S. W. J. Org. Chem. 1991, 56, 1845. (h) Kevill, D. N. In Advances in Quantitative Structure-Property Relationships; Charton, M., Ed.; JAI Press: Greenwich, CT, 1996; Vol. 1, pp $81-115$.

9. (a) Castro, E. A.; Ibanez, F.; Salas, M.; Santos, J. G. J. Org. Chem. 1991, 56, 4819. (b) Castro, E. A.; Salas, M.; Santos, J. G. J. Org. Chem. 1994, 59, 30. (c) Chrystiuk, E.; Williams, A. J. Am. Chem.
Soc. 1987, 109, 3040.

10. (a) Lee, I.; Sung, D. D.; Uhm, T. S.; Ryu, Z. H. J. Chem. Soc., Perkin Trans. 2 1989, 1697. (b) Yew, K. H.; Koh, H. J.; Lee, H. W.; Lee, I. J. Chem. Soc., Perkin Trans. 2 1995, 2263. (c) Guha, A. K.; Lee, H. W.; Lee, I. J. Chem. Soc., Perkin Trans. 2 1999, 765. (d) Hoque, Md. E. U.; Dey, N. K.; Guha, A. K.; Kim, C. K.; Lee, B.-S.; Lee, H. W. Bull. Korean Chem. Soc. 2007, 28, 1797. (e) Hoque, Md. E. U.; Lee, H. W. Bull. Korean Chem. Soc. 2007, 28 , 936.

11. Kevill, D. N.; D’Souza, M. J. J. Chem. Soc., Perkin Trans. 2 1997, 1721.

12. Kevill, D. N.; Kim, J. C.; Kyong, J. B. J. Chem. Res., Synop. 1999, 150

13. Kyong, J. B.; Ryu, S. H.; Kevill, D. N. Int. J. Mol. Sci. 2006, 7, 186.

14. Lee, I.; Koh, H. J.; Park, Y. S.; Lee, H. W, J. Chem. Soc., Perkin Trans. 2 1993, 1575. 